\title{
Towards a Likeability Framework that meets Child-Computer Interaction \& Communication Sciences
}

\author{
Bieke Zaman \\ CUO, Katholieke Universiteit Leuven \\ Parkstraat 45 bus 3605, 3000 Leuven, Belgium \\ bieke.zaman@soc.kuleuven.be
}

\author{
Vero vanden Abeele \\ e-Medialab, GroupT-Leuven Engineering School \\ Vesaliusstraat 13, B-3000 Louvain, Belgium \\ vero@groept.be
}

\section{(Co-authors, listed in reverse alphabetical order)}

\begin{abstract}
This paper discusses the quest for a framework that helps to research and design technology that supports fun activities of preschoolers in the home environment. We therefore review literature within Child-Computer Interaction and the Uses \& Gratifications framework in Mass Communication Sciences. We propose that in order to be likeable, a product should fulfill the gratifications of the user. We conceptualize interactive toys and games no longer as tools but as media. Through the use of probes and observations, we adapt and validate our framework to arrive at a final classification of gratifications. Our framework enumerates five important gratifications of preschoolers: (1) challenge \& control, (2) social experiences, (3) fantasy, (4) creative \& constructive expressions, and (5) body \& senses. Furthermore, we detail how basic needs, individual characteristics and societal aspects complement the Likeability Framework.
\end{abstract}

\section{Keywords}

Likeability Framework, preschoolers, cultural probing, Uses \& gratifications, Child-Computer Interaction, Mass Communication Sciences

\section{INTRODUCTION}

Currently, computing power is moving beyond the desktop and into everyday objects and games. Consequently, the focus has shifted from the workplace to the home and from productivity tools to software applications. Similarly, the focus has shifted from efficiency and effectiveness to pleasure and joy of use. Often this focus is indicated as 'the user experience' or a more holistic approach towards the design of applications. This approach not only considers usability, with its strong emphasis on cognition, but addresses emotion as well [20]. However, with this new focus on enjoyment, a need for new methods, heuristics, models, frameworks and theories to ground research and design has come to the surface.

LEAVE BLANK THE LAST $2.5 \mathrm{~cm}$ (1”) OF THE LEFT COLUMN ON THE FIRST PAGE FOR THE COPYRIGHT NOTICE.
Task analysis, contextual inquiries, personas, scenarios, usability tests, expert reviews, etc. are well documented and well established approaches to the design and evaluation of functional tools, but how do we go about something that is harder to grasp? How do we go about designing for fun? How do we measure likeability? Especially for a target group that is far from the world of adults, how can we design experiences that address fun and play, rather than productivity and efficiency?

The Human-Computer Interaction community is fully aware of the need for theories and methods to ground a human-centered approach to fun applications. The recent book 'Funology' [4] is entirely focused on this matter as was a recent issue of Transactions [3]. With CuTI [11], a research project on designing interactive toys for preschoolers in the home environment, we came across the same issue. Which methods, models and theories could guide us in designing interactive experiences that are fun? This paper describes our quest for a new framework to guide our design and the solutions we turned to. It is a first attempt to define a framework that can be used for likeability analysis, design and evaluation of applications that are aimed to be fun. To do this, we shift from a usability perspective to a media perspective [14]. Acknowledging that we are designing a medium rather than a tool, we use a framework that is well known in Mass Communications Sciences, the Uses \& Gratifications (U\&G) approach. We feel that this framework unifies research findings from the field of Child-Computer Interaction (CCI) with findings of Communication Sciences. We demonstrate how we adapt and devise the U\&G approach into our Likeability Framework for the design of interactive toys for young children.

This paper begins with a definition of the scope of our research purpose. We explain the need for a framework and why we turn towards the Uses \& Gratifications framework. The next section of the paper summarizes the most important likeability factors revealed in both U\&G and CCI research. Then, we elaborate and define our Likeability Framework. Finally, we discuss the challenges of our new framework and presents ideas for further work. 


\section{SCOPE OF OUR PROJECT AND THE NEED FOR A FRAMEWORK}

The CuTI-research project aims at the design of interactive toys for preschoolers in the home environment [11]. The first phase of our design process entailed the creation of empathy with the target group, idea generation for innovative toys and tracking of design requirements. We wanted to reveal those particular needs that are important to support playful behaviour and fun activities of preschoolers in order to inform the design of interactive toys and tangible games in a later stage. During one week, we researched eight preschoolers and their families at home, using an ethnographically informed research approach. In particular, we used cultural probe packages in the form of a fun logbook combined with participant observations. For a detailed discussion of the research method and results we refer to [1].

Although the CuTI project is focused on the design of a toy, we did not want to limit our observations to existing toys and playful technologies of children. We believe that analyzing existing solutions only would limit us in inspiring new and innovative designs. Therefore, we broadened our research scope and investigated all activities that children reported to be fun. In itself, there is no true difference in the experience of mediated and non-mediated fun [33].

From the design and interpretation of the findings of our ethnographically informed research methodology, however, emerged the need for a framework and a theoretical basis. The richness of the data, the situatedness of the observations and the involvement of the observer required for a grounding in a theory to direct the lens. "It is impossible to conduct an ethnographic study without a theoretical perspective. With the rich stimuli of the real world, it is necessary to filter and focus. Those who lack a perspective can be expected to cobble together a perspective on the fly, one that may be uninformed, fraught with investigator bias. The leading theoretical perspectives for ethnographically-oriented human-computer interaction studies are activity theory (Nardi, 1996a), distributed cognitions (Hutchins, 1994; Roger and Ellis, 1994) and situated action (Suchman, 1987)" [21, 31].

Unfortunately, the three perspectives mentioned above are focused on how knowledge and action is distributed and regulated in the workplace. The emphasis on 'knowledge' however contrasts with our aim for 'fun' and the workplace is clearly not the same as the home environment.

In our search for a suitable framework for likeability research, we did not find an appropriate framework to ground research activities that focus on children and interactive toys. Consequently, we were in need for a framework, a theory that could help us direct and focus our lens. Because of our background in Communication Sciences, the attention was turned towards the Uses \&
Gratifications framework, a well-established body of media research.

In this paper, we describe how we elaborated a new framework that fits into the U\&G paradigm and that unifies research findings within Child-Computer Interaction (CCI).

\section{USES AND GRATIFICATIONS}

In this paragraph, we explain the U\&G paradigm. In order to use this framework within CCI however, we have to make three assumptions. These assumptions will be discussed as well.

\section{The U\&G paradigm}

In Mass Communication Sciences, the Uses \& Gratifications (U\&G) paradigm focuses on how frequently and especially why certain types of (genres within) media are used [15, 20, 25, 27] by whom. The basic premise of the U\&G paradigm is that people actively choose specific media to fulfill particular gratifications. This approach contrasts with the media effects tradition that investigates what media do to their passive audience.

The diagram below (Fig.1) is a simplified model taken from Sherry \& Lucas [16, 30] and based on Rosengren's [25] view on the U\&G paradigm. Three main components can be distinguished that explain media use: basic needs, individual characteristics and society. The three components thus drive the motives (or 'gratifications sought') for uses and these uses can fulfill the gratifications of the user ('gratifications obtained'). Basic needs should be considered as the biological and psychological infrastructure that informs all of human behaviour. Often Maslow's [19] needs are taken as a starting point. Society points towards the social and contextual influences. Individual characteristics encompass typically the psychological and demographics of the audience.

We found Rosengren's [25] framework of the U\&G approach particularly interesting because it does not only report on the more psychological influences but also elaborates on the societal (contextual) factors and media structures. Similarly to HCI, U\&G combines a perspective on media use with social and psychological characteristics.

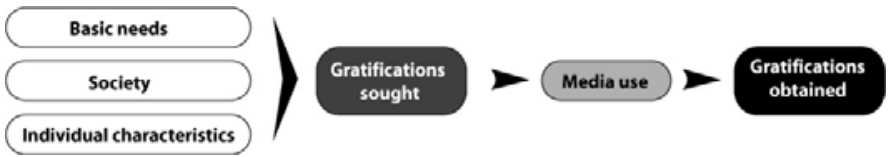

Figure 1. The U\&G paradigm

The U\&G model does not specify how exactly the mix of societal, individual characteristics and basic needs leads to certain types of media behaviour, rather it calls upon researchers to fill in these details. However, U\&G does acknowledge that no single factor drives media use; it is the 
mix and the interaction among needs, contextual factors and individual characteristics that predict media use.

This short introduction to Uses \& Gratifications clarifies why we consider the U\&G framework appropriate to analyze why people (i.c. children) like or do not like certain products. However, to accept this framework within CCI, we have to make to following assumptions.

\section{Assumption 1: Interactive artifacts can be seen as media}

The choice for the U\&G framework implicates that we abandon a paradigm that is current in Human Computer Interaction, the usability perspective. We no longer view artifacts as tools; instead we look upon applications as media [14]. The adaptation of the U\&G framework in likeability research demands the acceptance that artifacts like interactive toys and games can be seen as media. Therefore we address our first assumption; the U\&G framework requires us to accept that interactive toys, games, and other artifacts that support play activities can be seen as media.

Assumption 2: Users are active in their choice of media $\mathrm{U} \& \mathrm{G}$ starts from the promise that the audience is active; an important part of mass media use is assumed to be goaldirected [15]. Instead of being passive bystanders, people choose to engage in a medium and their choice reflects their need for gratifications. Thus need gratification and media choice lies within the audience member. The perspective of an active audience is illustrated by Schramm, Lyle and Parker [28, p. 169] who state that "in order to understand television's impact and effect on children, we have first to get away from the unrealistic concept of what television does to children and substitute the concept of what children do with television."

Clearly this paradigm that one actively chooses to deal with a certain medium based on particular needs and the need for gratifications, is very similar to the user-centered approaches that are prevailing in HCI. For instance, we can refer to the goal-directed design approach of Cooper [7] or the contextual inquiries by Karen Holtzblatt [13], where design requirements are based on needs in order to fulfill goals, wishes and dreams.

Similarly to communication scholars that follow a U\&G perspective, likeability researchers thus a priori presume that the user is active in his/her choice to use or not to use media/applications for certain reasons.

Assumption 3: Likeable products fulfill gratifications Finally, similarly to HCI researchers that approach users as purposeful and task-oriented, U\&G researchers make the assumption that media serve the user's needs or goals in order to fulfill gratifications. Especially in the context of designing for fun, where the goal is not to produce output or accomplish productivity tasks but rather enjoying the process, this is an interesting perspective. With regard to the U\&G paradigm, the division is made between gratifications that are sought (GS) and those that are obtained (GO) from media use. To meet the user's needs, gratifications obtained should correspond with gratifications sought. In this respect, we formulate our final assumption: in order to design likeable products, we need to fulfill those gratifications that users seek in specific medium.

\section{WHAT HCI AND U\&G TELL US ABOUT CHILDREN AND PLAY}

In this paragraph, we review existing literature, both within the field of Communication Sciences as well as Human/Child-Computer Interaction that report on why people use technologies. First, we discuss literature in the domain of Human-Computer Interaction. More particularly, we summarize research findings on what children want in technology. Then, we describe relevant typologies for fun applications within the Uses \& Gratifications framework. Together, these findings provide a first attempt to define a Likeability Framework.

\section{$\mathrm{CCl}$ : What young children seek in toys and games}

From our literature review, we found that five categories have been repeatedly reported as explanatory factors for what children want in technology.

First of all, children like control [9,18,24,17,12,10]. By control we include: control over the situation, the environment, over one's self and over others. During learning processes, children easily loose their patience. To give them more empowerment during play, three conditions should be realized. Firstly, the result of an activity should be contingent upon the child's behaviour. Secondly, children should have sufficient choice options. Thirdly, the child should have enough 'power' to realize the most important tasks and actions $[12,17,18]$. It should be stressed that the possibility of control is most important to cause an enjoyable experience, rather than the actuality of control [8].

Secondly, children seek social experiences [8, 9, 10]. Similarly to adults, children are social beings who experience solitude mostly as a negative experience [8].

Thirdly, children like to express themselves $[9,10]$ in many forms: sound, visuals, movement, physical appearance, etc. This is confirmed by Wyeth \& Diercke [34] who found that children like activities in which they can be creative and constructive.

Further, challenge is important to captivate children [18, $24,17,12,8,10]$. In order to obtain the right level of challenge, clear goals and performance feedback (e.g. rewarding) are necessary. An activity is challenging if the outcome of its purpose is uncertain but when one has a chance of completing. Other situations that facilitate challenge are when information is now and then missing and when coincidence has a limited effect. However, when 
something is too complicated and difficult, children might become anxious. In contrast, if something is too easy, it causes boredom. $[18,24,17,12,8,10]$. Notice that this definition of challenge is similar to the notion of control.

Finally, children like fantasy [3, 8, 18]. By fantasy, the evocation of mental images of physical objects or situations is meant. This implies activities that address role-playing, pretence play, mimicry and make-believe. With preschoolers, make-believe becomes more and more complex [2]. Children younger than three year rely on realistic objects to pretend situations. These situations are mostly a copy or imitation of adult's actions. From the age of three year, children can easily imagine objects or situations without an immediate link with real life [2]. To realize an optimal level of fantasy, the child's emotions must be addressed so that he/she feels physiologically involved. Another way to realize fantasy is by means of a successful story line that gives meaning to play activities. By fantasy, children can go beyond the boundaries of normal experiences. This can make them feel more than what they actually are [8].

To summarize, we list the following important categories of what children want in technology:

1. Control

2. Social experiences

3. Expression

4. Challenge

5. Fantasy

\section{Uses \& Gratifications framework}

Because of our knowledge of U\&G and especially studies on gratifications of videogames by Sherry \& Lucas [16, 30], we turned our eye to review existing classifications of gratifications from a U\&G perspective. We first discuss the classification of traditional media that is well known and then demonstrate how Sherry \& Lucas adapted the framework towards videogames.

\section{$\cup \& G$ and traditional media}

Originally, U\&G was used to study traditional mass media, such as television and newspapers. When looking at gratifications from traditional media, four areas of gratifications often appear [4, 20].

1. Information \& surveillance: The need to inform about the world, to fulfill curiosity or to get answers on practical problems one experiences in real life.

2. Personal identity: Empathy with characters (e.g. actors in a movie) because of the association of their personality and life with our own.

3. Integration, social interaction, personal relationships: This refers to gaining insight into the situations of other people in order to achieve a sense of belonging. Media also provide inspiration and information to talk about with friends, relatives, colleagues etc. This common topic of conversation facilitates and strengthens our personal relationships.

4. Entertainment, diversion, escapism: This last media usage reports on the need for pleasure and enjoyment. In this case, people use media to pass time, feel free from all their problems, escape from the real world by entering a new world of fantasy.

\section{$U \& G$ and interactive media}

$U \& G$ is also seen as an excellent way to study new media. New media credit users with even more control over their own activities. The active audience paradigm prevalent in U\&G aligns well with new interactive media such as internet or video games. In this respect, mass media scholars promote an adaptation of the U\&G framework to new technologies. "A challenge is for researchers to adapt and mold the current conceptual framework to deal with new communications technologies” [26, p. 241].

We found Sherry \& Lucas' classification of gratifications $[16,30]$ especially useful. They defined six gratifications why people play video games:

1. Competition: To be the best player of the game

2. Challenge: To push yourself to beat the game or get to the next highest level

3. Social interaction: To play as a social experience with friends

4. Diversion: To pass time or alleviate boredom

5. Fantasy: To do things that one cannot do in real life

6. Arousal: To play for excitement

Although this classification is adapted for researching new media and more particularly video games, we see that some gratifications are similar to those of traditional media. The choice for Sherry \& Lucas' classification of gamegratifications is well considered because of the close link to our objective to design innovative toys and games.

\section{A unified classification based on literature}

To summarize, since no likeability framework existed that could be used to guide us in researching and designing interactive experiences for children, we first reviewed literature on Child-Computer Interaction. This revealed a classification of five components that explain what is needed to aim at fun for children.

We then turned our head towards Communication Sciences and found a great resemblance with the Uses \& Gratifications paradigm. More particularly, there is an overlap with Sherry \& Lucas' classification.

Although there is a great resemblance between both classifications, we did not encounter the importance of 'diversion' and 'arousal' in CCI literature. In U\&G literature though, the need for creative \& constructive 
expression does not seem to be of importance with adolescents who play video games.

To conclude our primary framework, we added up gratifications of both disciplines to arrive at the following classification (Table 1): 1) Challenge, 2) Control, 3) Social experiences, 4) Fantasy, 5) Diversion, 6) Arousal and 7) Creative \& Constructive expressions.

Table 1 Our classification based on CCI and U\&G literature

\begin{tabular}{|l|l|l|}
\hline $\begin{array}{l}\text { CHILD } \\
\text { COMPUTER } \\
\text { INTERACTION }\end{array}$ & $\begin{array}{l}\text { U\&G } \\
\text { (COMM.RESEARCH) }\end{array}$ & OUR CLASSIFICATION \\
\hline Control / challenge & Competition & Challenge \\
\hline Control / challenge & Challenge & $\begin{array}{l}\text { Control } \\
\text { Social experiences }\end{array}$ \\
\hline Social experiences & Social interaction & Fantasy \\
\hline Fantasy & Fantasy & Diversion \\
\hline$/$ & Diversion & Arousal \\
\hline$/$ & Arousal & $\begin{array}{l}\text { Creative \& Constructive } \\
\text { expressions }\end{array}$ \\
\hline $\begin{array}{l}\text { Creative \& } \\
\text { constructive } \\
\text { expressions }\end{array}$ & $/$ & \begin{tabular}{l} 
\\
\hline
\end{tabular}
\end{tabular}

\section{CLASSIFICATION TESTED AND REFINED THROUGH} CULTURAL PROBING

With this conceptualization of gratifications of games and components of playful technologies, we started our observations. We wanted to employ our classification to interpret the findings of the cultural probing sessions. However, we also wanted to use our findings as validations of the classification. Because we focused on young children instead of adolescents as U\&G researchers Sherry \& Lucas did, we expected difficulties to occur. Also, we did not limit ourselves to videogames but broadened the scope to 'fun activities'. Similarly, we also expected inconveniences since we investigated fun activities in the home environment contrary to most CCI research that takes place in an educational setting. Overall, we thus expected that our classification might not be complete and need some additional changes.

Our quest for a suitable likeability framework bears in some respect a resemblance to a 'wicked problem', which is typical for design research. Similarly to wicked problems that are open-ended in that they cannot be objectively defined, our framework is a first attempt, open for testing and validation [14]. Also, just like a wicked problem must be solved before one can define it, we proposed a framework that is far from definitive. Although, we used our classification to ground the research activities, at the same time the empirical research served as a validation of this first classification. For more information on the methodological approach and results of our probing sessions, we refer to [1].

\section{The results of our observations}

First of all, our probing and observation analysis revealed that there is no difference between 'challenge' and 'control'. Accepting Csikszentmihalyi's conceptualization of control [8], we felt that 'control' was targeted towards the self and therefore should be classified under 'challenge'. "Can I do this, am I skilled, smart, quick enough?”. When 'control' had to do with control of others, we took the theory of Schutz [29] and classified this as 'social experience'. Consequently, we no longer felt the need for a separate 'control' gratification. 'Control' was divided over 'social experiences' and 'challenge'.

Secondly, our probing sessions revealed the importance of physical sensations and sensory stimulation. We did not encounter this gratification in previous CCI research, nor in U\&G studies. However, Roger Caillois [6], who was one of the first to construct a taxonomy of games, dealt with the act of 'being physically out of control'. He calls this type of game play 'vertigo'. Our preschoolers listed a lot of fun activities that pointed towards running, jumping, moving around. Therefore, we first added 'vertigo' to our classification. However, our preschoolers also listed eating, massaging and tickling as fun activities. They further liked listening to music and sounds or watching bright pictures. We thus felt that 'vertigo' was too limiting and did not address all sensory stimulation. Consequently, we opted for the category 'Body \& Senses' because it includes both physical sensations and sensory stimulation.

A last noticeable element is that two typical U\&G gratifications, diversion and arousal, were not relevant for preschoolers. Neither the probe packages, nor our observations or interviews emphasized that preschoolers like media because it alleviates boredom (diversion). The same goes for arousal. Although children were often enthusiastic and excited about some activities, the underlying reason then fitted more in one of the other gratifications such as 'Challenge \& Control' or 'Body \& Senses'.

\section{Towards a framework for likeability}

Based on the literature review and our interpretation of fun activities of preschoolers in the home environment, we concluded our framework. Figure 2 presents this Likeability Framework.

It illustrates how an interaction between basic needs, contextual societal factors and individual characteristics effects the gratifications children get or seek. In total, we discern five different gratification areas that make things fun and likeable. We hereby assume that the more a product fulfills these gratifications, the more the product will be likeable for preschoolers. Furthermore, basic needs, contextual factors and individual characteristics affect the gratifications children get or seek. 


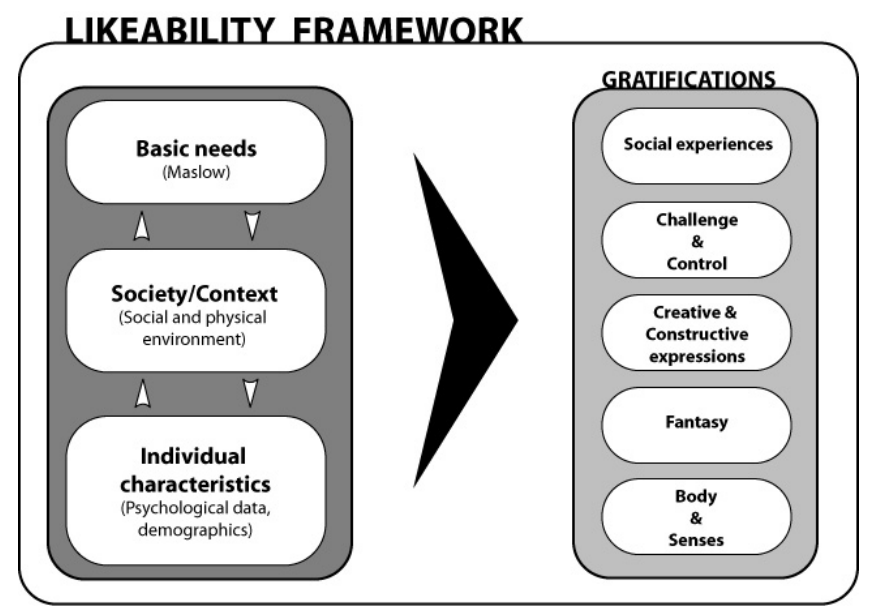

Figure 2. Towards a Likeability Framework

\section{Gratifications}

In total, our framework reports on the importance of five gratifications.

\section{Challenge \& Control}

With 'challenge' and 'control', we adopt Czsickentmihalyi's theory of flow [8]. Flow theory deals with the fact that in order to be truly challenging and 'absorbing' one needs to address the right skill levels. Too easy and it becomes boring; too hard and it becomes frustrating. If the challenge is tuned right, however, activities become so rewarding that they are done just for the sake of doing it.

\section{Social experiences}

With this category, we refer to fun activities that are mainly pointed towards being together with others. Based on Schutz' interpretation [29], we distinguish between activities that point towards inclusion (being a member of a social group), affection (expression of being accepted) and control of others (being able to have an influence on others).

\section{Fantasy}

With 'fantasy', we include all activities that address roleplaying, pretense play, mimicry and make-believe.

\section{Creative \& constructive expressions}

This gratification concerns activities such as drawing, painting, claying, modeling, handicrafts and also for instance constructing, building or carpentry.

\section{Body \& Senses \\ Finally, we found physical sensations and sensory}

stimulation to be very important for the age group of 5years-old.

Basic Needs

Most often, U\&G starts from Maslow's [19] description of needs and then especially the need for belongingness and love, the need for esteem and the need for selfactualization. To look at basic needs for fun activities for preschoolers, the theory of Sutton-Smith [32] was found particularly interesting. He sees play as a mechanism for generating behavioural mutation, thus helping to deal with the world and survive. Similarly, developmental psychologist Oerter [23] sees play as a need for 'coping with reality', a process of negotiation to learn to deal with reality. We accept that all preschoolers have a basic need to play in order to develop and learn to deal with the world. Summarizing, preschoolers' basic needs can be summarized as the need for playing, the need to be loved, the need to be respected and the need to develop.

\section{Society and context}

Since children are our main target group, insight in their social and cultural context is crucial. Adults inevitably forget what it is to be a child. The contextual landscape has changed so that adults can no longer get what it is nowadays to grow up as a child. Moreover, one child differs from another and may be grown up in a different social and physical environment.

As for the social environment, we found that siblings have a clear influence on the gratifications sought and obtained. Younger children tend to want to play along with older siblings and admire and strive for the same. Older children tend to be bothered by their younger siblings and tolerate this at best. Anyhow, older children certainly aim for distinguishing themselves from the younger siblings, showing they can do more complex things.

Besides the family composition, parents clearly have a saying in the play of the child. Parents both afford and constrain fun activities of preschoolers. Not surprisingly parents like their children to learn and engage in 'meaningful' activities.

Although parents influence and place constraints, children are still active in their choice. They also influence their parents in return. This is clearly a two-way interaction.

\section{Individual characteristics}

Individual characteristics typically encompass the psychological and demographics of the audience. As for our target group, we addressed eight five-year-olds of which five boys and three girls, randomly selected from an elementary school in the environment. All children were living in Flanders, a relatively wealthy part of Europe. 
With regard to the cognitive development of our target group, we address the following characteristics. Five year olds are at the end of the pre-operational phase.

Piaget stressed that in this phase, children cannot yet think and operate in a logic manner [2]. They often use magical thinking to explain phenomena: "It rains because the clouds are crying." Preschoolers' make-believe becomes more and more complex. Make-believe concerns the imagination of objects and events without any immediate link to the real world. Piaget also claimed that 5-years-old have an egocentric view. They cannot adopt a viewpoint other than one of their own. Further, 5-year-olds still display egocentric thinking. This does not imply that they are selfish. These children are however unable to imagine the perspective of others.

As regards their physical development, preschoolers become better coordinated in motor skills such as running, jumping, skipping, throwing and catching. The control of their hands and fingers increases so that they can e.g. dress, tie shoes or write/copy some letters.

\section{DISCUSSION}

The first thing a designer has to reveal is what people seek in (future) technologies. Researchers who evaluate existing technologies try to know whether users find in technologies what they want or what they like. Likeability research before, during and after the design phase needs a framework to analyze the results. In this paper, a Likeability Framework is elaborated. The framework is based on the Uses \& Gratifications perspective, integrates the main results found in the domain of Child-Computer Interaction and is tested through our own research.

Our Likeability Framework should be useful for different research purposes. In general, the framework should help interpreting the likeability of activities and products for children. Further, it can be applied to reflect on the results of cultural probing but also during likeability test sessions to explain why a product is or is not fun. Finally, it might serve as a guide during design research.

Our Likeability Framework illustrates how an interaction between basic needs, contextual societal factors and individual characteristics effects the gratifications children get or seek. The first factor concerns children's basic needs such as the need for playing, the need to be loved, the need to be respected and the need to develop. Secondly, the context represents the social and physical computing environment, especially the influences of parents and siblings. Thirdly, individual characteristics such as cognitive and physical development are included. These three factors influence children's gratifications. In total, we discern five different gratification areas that make things fun and likeable: (1) challenge \& control, (2) social experiences, (3) fantasy, (4) creative \& constructive expressions, and (5) body \& senses. In other words, we assume that the more a product fulfills these gratifications, the more the product will be likeable for preschoolers.

\section{FURTHER WORK}

The framework elaborated in this paper, however, is far from established. The framework has only been tested and improved once to analyze the results of a cultural probing session. Now the path is opened for further research.

First of all, one should test whether this framework is really focused on preschoolers of all different backgrounds. All our preschoolers had two parents and lived in a house with a garden in a relatively wealthy neighborhood. But what about single parent families who live in an apartment, for instance? And in which extend is this framework also applicable to younger or older children?

Further, thanks to our broad research scope towards fun activities in general, we found that physical sensations and sensory stimulation are very important to preschoolers. We did not encounter this gratification 'body \& senses' in previous research. However, if we had limited our scope to play or toys, we would not have found this additional gratification. Now we know that addressing preschoolers' senses is important, the potential success of tangible and ambient technologies increases. Therefore, a thorough literature review and iterative testing is needed and already planned to adapt our framework to research and design tangible/ambient applications.

In sum, we take up the challenge to improve our framework to make it perfectly suitable to research likeability with preschoolers of all contextual backgrounds in the home environment and design tangible and ambient technologies.

\section{REFERENCES}

1. Abeele, V. Vanden \& Zaman, B. (Under Review). Reflection in Action: An integrated use of cultural probes. Proceedings of the conference on Interaction Design and Children. Denmark 2007

2. Berk, L.E. Development through the lifespan, third edition. Allyn \& Bacon, 1999.

3. Blumler, JG and Katz, E. The uses of mass communications: current perspectives on gratifications research. Sage publications, 1974.

4. Blythe, M., Hassenzahl, M. and Wright, P. (eds.) Funology. Interactions. 11,5 (entire issue) (2004).

5. Blythe, M.A., Overbeeke, K., Monk, A. F., and Wright, P.C.(eds.). Funology. Form Usability to Enjoyment. Kluwer Academic Publishers, 2004.

6. Caillois, R. Man, Play, and Games. Trans. Meyer Barash. Chicago: U Illinois P, 2001.

7. Cooper, A. and Reimann, R.M. About Face 2.0: The Essentials of Interaction Design. Wiley, 2003. 
8. Csikszentmihalyi, M. FLOW, The classic work on how to achieve happiness. London: Rider, 2002.

9. Druin, A., Bederson, B., Boltman, A., Miura, A., Knotts-Callahan, D. and Platt, M. Children as our technology design partners, pp. 51-72 in A. Druin (ed). The Design of children's technology, 1999.

10.Druin, A. and Inkpen, K. When are personal technologies for children?, Personal technologies 5,3 (2001), 191-194.

11.e-Medialab, Group $\mathrm{T}$ Leuven Engineering School. CuTI, Cuddle Toy Interfaces for toddlers and preschoolers, http://wiki.groept.be/confluence/display/Cu/Home

12. Fabricatore, C., Nussbaum, M. and Rosas, R. Playability in Action Videogames: a Qualitative Design Model. Human Computer Interaction 17, 4 (2002), 311368.

13.Holtzblatt, K. and Jones, M. Contextual inquiry: A participatory technique for system design, 2003. In D. Schuler and A. Namioka (Eds.), Participatory Design: Principles and Practices. Erlbaum., NJ, 1993, 177-210.

14. Hult, L., Irestig, M., and Lundberg, J. Design perspectives. Human-computer Interaction. 21(1), (2006), 5-48.

15.Katz, E., Blumler, J.G. and Gurevitch, M. Uses and Gratifications Research. Public opinion quarterly 37,4 (1973), 509-523.

16.Lucas, K. and Sherry, J.L. Sex differences in video game play: a communication-based explanation. Communication Research, 31(5), 2004, 499-523.

17. Malone, T. W. Heuristics for designing enjoyable user interfaces: lessons from computer games. In proceedings of the 1982 conference on Human factors in Computing Systems (1982), ACM, Addison-Wesley, 63-68.

18. Malone, T.W. and Lepper, M. R. Making learning fun: a taxonomy of intrinsic motivations for learning. In $\mathrm{R}$. E. Snow and M.J. Farr (eds.), Aptitude, learning and interaction III Cognititve and affective process analysis, Lawrence Erlbaum, Hillsdale, N.J., 1987.

19. Maslow, A. Motivation and personality. New York: Harper, 1954.

20. McQuail, D. McQuail's mass communication theory. London: Sage, 2000.
21.Nardi, B. A. Handbook of Human-Computer Interaction, M. Helander, T.K. Landauer, P. Prabhu (eds.), Elsevier Science, 1997.

22. Norman, D. Emotional Design: Why we hate or love everyday things. Basic Books, NY, 2003.

23. Oerter, R. Spiel as Lebensbewältigung. In Jürgen Fritz \& Wolfgang Fehr, Handbuch Medien: Computer Spiele. Bonn: Bundeszentrale für politische Bildung, 2000, 5965

24.Pagulayan, J. R., Keeker, K., Wixon, D. and Romero, R.L. User-centered design in games. In J. Jacko and A. Sears (eds), Handbook of Human Computer Interaction, Lawrence Erlbaum Associates Inc. London, 2003.

25. Rosengren, K.E. Uses and gratifications: A paradigm outlined. In J.G. Blumler and E. Katz (Eds.), The uses of mass communications: Current perspectives of gratifications research, 269-286. Beverly Hills, CA: Sage, 1974.

26. Rosengren, K. E., Wenner, L. A. and Palmgreen, P. Media Gratifications Research. Current perspectives. Beverly Hills (Calif.): Sage, 1985.

27. Ruggiero, T. E. Uses and Gratifications theory in the $21^{\text {st }}$ Century. Mass communications \& Society, 3,1 (2000), 3-37.

28. Schramm, W., Lyle, J. and Parker, E. Television in the lives of our children. Palo Alto, CA: Stanford University Press, 1961.

29. Schutz, W. C. FIRO: A three-dimensional theory of interpersonal behavior. New York: Rinehart and company, 1958.

30. Sherry, J. (2006). Playing video games: motives, responses, and consequences, P. Vorderer and J. Bryant (eds.), Erlbaum.

31. Suchman, L. A. Plans and situated actions: The problem of human-machine communications. Cambridge, UK: Cambridge University Press, 1987.

32. Sutton-Smith, B. The Ambiguity of Play. Cambridge, Massachussets \& Londen, 1992.

33. Vorderer, P., Klimmt, C. and Ritterfeld, U. Enjoyment: at the heart of media entertainment. Communication theory. 14,4 (2004), 388-408.

34. Wyeth, P. and Diercke, C. Designing cultural probes for children. In proceedings of OZCHI (2006). 